\title{
Improving Depression Treatment by Integrated Care
}

\author{
KATHRYN M. ROST, PhD
}

\begin{abstract}
OBJECTIVE: To identify the clinical and economic implications of depression in the workplace and review how integrated care models can improve overall patient outcomes.

SUMMARY: Depression is a significant financial burden to the employer due to lost days of work and decreased productivity. Employers are demanding return on the investment for their increasing health care expenditures. The cost of depression to employers may be contained by delivering care using integrated models that leverage primary care provider treatment with care management and mental health consultation.
\end{abstract}

CONCLUSION: There is a need to reduce silos in the organization and financing of mental health care to prevent cost shifting that provides no benefit to patients, payers or providers. Poor mental health care will likely lead to a rise in absenteeism and presenteeism.

KEYWORDS: Depression, Integrated care, Employer, Absenteeism, Presenteeism, Productivity

J Manag Care Pharm. 2005;11(3)(suppl):S5-S8
I $\mathrm{n}$ order to understand how we can improve the treatment of depression, it is useful to assess the problem from different perspectives. We know much about the impact of depression and its treatment from the patient and provider perspectives, but we rarely consider the ramifications of the disease on the purchaser. Purchasers have considerably more leverage than they currently exert in the quality of care health systems deliver. In particular, purchasers may be able to encourage health systems to provide better quality care by advocating for the adoption of integrated care models that are emerging for the treatment of depression and other chronic diseases. Before purchasers can advocate for these models, they must have evidence of the clinical and economic value these models produce.

\section{Depression in the Workplace}

The private employer insures about $60 \%$ of Americans and is a major purchaser of health care for most working Americans. ${ }^{1}$ Because 1 out of every 10 Americans suffer from depression annually, the likelihood of a coworker being affected by depression in the workplace is high. ${ }^{2}$ In fact, absenteeism from depression is estimated to be about 1.6 days of work lost per employee per month which is equivalent to about 1,500 lost days per month for a company with 1,000 employees. ${ }^{3}$ Absenteeism results in increased workload for other employees, reduced output, and lost income from hiring temporary workers.

In addition, reduced productivity at work, or "presenteeism," is a significant but underrecognized concern for employers. It has been reported that employees who suffer from depression work at about $70 \%$ of their optimal productivity. ${ }^{4-7}$ Also, $62 \%$ of employees report decreased mental functioning that ultimately affects their output and time management.

In 2000, depression cost employers an estimated $\$ 51.5$ billion. ${ }^{8}$ Approximately $70 \%$ of that cost was due to absenteeism while the rest was attributed to productivity loss. This is a significant financial problem for employers, who are already paying $\$ 26.1$ billion for depression treatment. ${ }^{8}$ Employers are faced with a complex issue-increased numbers of employees being diagnosed with depression, increased rates of treatment for depression, and increases in pharmaceutical costs. Employers are seeking newer and better solutions to this problem, ones that can demonstrate sufficient re tu mon investment to warrant adoption.

\section{Integrated Care Models}

There are a number of potential solutions to improve the clinical and economic outcomes of depression treatment. Integrated care models that are currently available focus on 3 aspects of care that are essential for the treatment of depression. The first step, using a screening tool, is to identify patients who may have depression. As we know, the majority of patients who receive treatment for depression do so from their primary care physician (PCP). ${ }^{9}$ The 


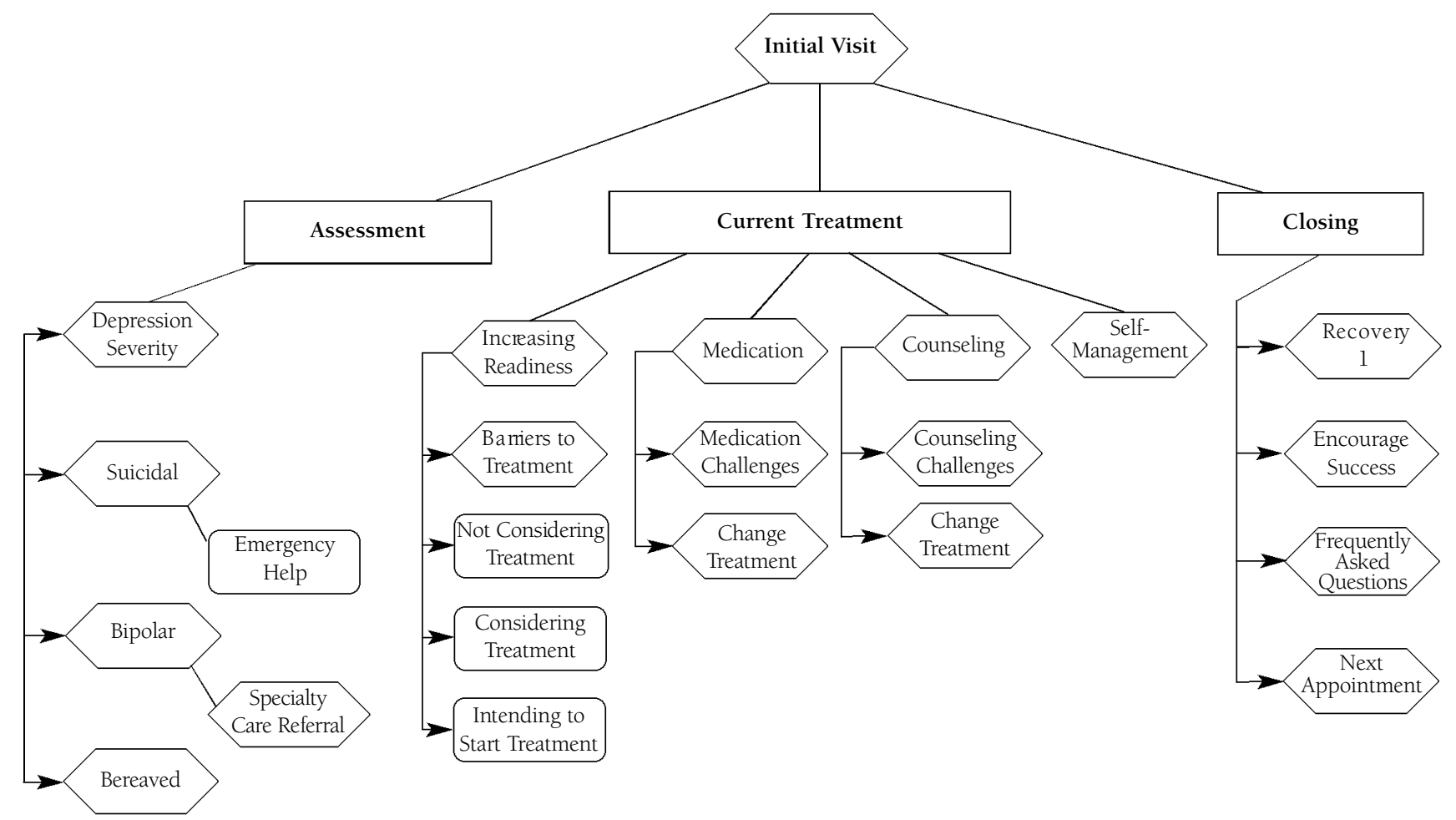

reason may be partly because managed care organizations are shifting the burden of depression and anxiety treatment away from mental health specialists to PCPs. ${ }^{10}$ In addition, to reduce cost, many managed behavioral health care organizations limit the number of specialty care visits a depressed patient can make..$^{11,12}$ Even in short PCP visits, simple screening tools for depression can aid the PCP in recognizing patients who may be at risk for depression or have clinically definable disease.

In our initial program designed 10 years ago, trained nurses identified patients with depression and provided care management to them over 2 years using a decision-tree care plan (Figure 1). Nurses assessed disease severity, educated patients about treatment options, and monitored their progress over time. In today's models, care managers are also supervised by either a psychiatrist or a pharmacist.

While pharmacists can provide patient education and monitoring, they also have unique expertise in providing alternatives for drugs that are intolerable or clinically ineffective. In the future, utilization of pharmacists may be the most costeffective solution for managing patients with complex medication regimens in the managed care setting. In addition, the shortage of psychiatrists may significantly increase the demand for advanced pharmacy practitioners to fill these care management needs.

\section{Impact of Model}

Integrated care models will in all likelihood increase the number of patients who are identified with depression and begin treatment. It has been estimated that $50 \%$ of all depressed patients in the primary care setting remain undiagnosed. ${ }^{13}$ In addition, the education integrated care models provide will result in greater patient understanding about the importance of treatment completion, which will, in turn, curb early discontinuation rates. More frequent contacts with care managers along with counseling about medication side effects should result in increased compliance. Patients frequently list intolerable side effects as the primary reason for discontinuing their treatment prematurely.

A national survey found that, in patients with probable anxiety or depressive disorder, only about 30\% received some form of appropriate treatment. ${ }^{14}$ Although identification of patients is an important first step, the field also needs to improve the treatment patients receive once they are identified. The process of ensuring that patients actually fill a prescription and then take the medication appropriately is complex, and we must find ways to bridge gaps in the process. Even after patients initiate therapy, there is still room for potential complications. Care managers can facilitate appropriate medication switches and encourage patients to continue treatment when the initial medication fails. They can also recommend 
dosage increases, if needed, to optimize therapy. Additionally, they can simply encourage patients to continue with therapy during the time it can take for antidepressant medications to take full effect. Often, patients are tempted to discontinue their medications during this time because of intolerable side effects while experiencing little clinical benefit.

\section{Outcomes Data}

We evaluated the clinical and economic outcomes of an integrated care model to demonstrate its value to potential purchasers. Over 2 years, about $74 \%$ of patients who received our intervention were in probable remission compared with only $40 \%$ of patients who received usual care. In addition to improving emotional role functioning to close to population norms, the model had a significant but smaller impact on physical functioning, possibly due to medical comorbidities commonly associated with depression. The cost of the program is $\$ 130$ per year with an additional $\$ 134$ per year for incremental treatment. Accounting for inflation for year 2005, the total cost of the model was estimated to be \$297 per year per treated depressed employee.

We recognized that patients improved clinically, but what other benefits accrued and to whom? Over 2 years, the intervention decreased the number of hours of work lost in the previous month from $\sim 20$ hours to 4 hours, resulting in an average reduction of 12.3 days of absenteeism, with an annual value of $\$ 648$ per participating employee (Figure 2). Over 2 years, the intervention also improved productivity at work in the previous 2 weeks, resulting in an average increase of $8.2 \%$, with an annual value of $\$ 1,982$ per participating employee (Figure 3).

It is possible for employers to calculate their retum on investment for their depression care program based on a business case model that I have developed. The retum on investment is dependent upon the ratio of annual savings with quality depression care to the cost of the depression care program and the additional treatment it stimulates. Return on investment is dependent upon various factors such as hourly wage, sick leave benefit, likelihood of increased revenue with increased productivity, likelihood of hiring temps to cover absent employees, the company's contribution to health plan premium, and the prevalence of depression in the specific employee population. The retum on investment calculation can be done for any company, health plan, or institution and is available at http://www.depression-primarycare.org/ organizations/employers/calculator.

\section{Conclusion}

Primary care providers are faced with a difficult task of addressing a variety of health issues during every visit. Integrated care models such as the one presented here can be the part of the solution to optimize clinical and economic outcomes in the primary care treatment of depression.

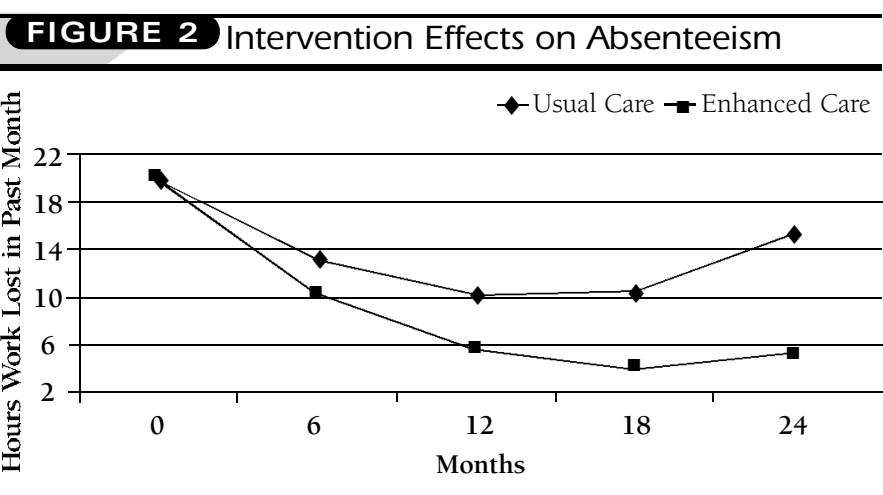

Average 12.3 day reduction over 2 years at an annual economic value of $\$ 648$ per depressed participant.

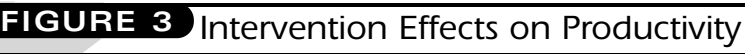
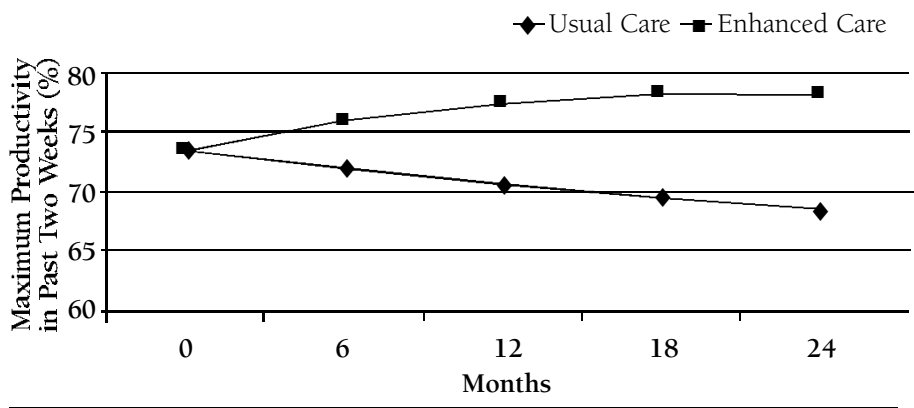

Average $8.2 \%$ increase over 2 years at an annual economic value of $\$ 1,982$ per depressed participant.

\section{ACKNOWLEDGMENTS}

The author wishes to acknowledge Mark Schwartz, MBA, for his work on the model for this study. She also acknowledges the physicians, office staff, and patients of the following participating primary care practices: Chatham Primary Care, Siler City, NC; Dunes Family Health Care, Reedsport, OR; Eau Claire Family Medicine, Eau Claire, WI; Enid Family Medicine Clinic, Enid, OK; Fergus Falls Medical Group, Fergus Falls, MN; Health East Eastside Medical Center, St. Paul, MN; Lynchburg Family Practice, Lynchburg, VA; Mile Bluff Clinic, Mauston, WI; Mountain Area Family Health, Asheville, NC; Northern Colorado Family Medicine, Greeley, CO; Oakwood Health Care Center, Westland, MI; Somerset Family Practice, Somerville, NJ; and University of North Dakota Center for Family Medicine, Minot, ND. She acknowledges her colleagues in the Quality in Depression Cooperative Agreement for their sound advice and assistance.

\section{DISCLOSURES}

Funding for this study was contributed by the National Institute of Mental Health and the MacArthur Initiative on Depression and Primary Care and obtained by the author. The author received an honorarium for participating in the symposium upon which this article is based. She discloses that she has received grant/research support from NIMH, the MacArthur Foundation, and the Robert Wood Johnson Foundation. 


\section{REFERENCES}

1. Lundy J, Finder B, Claxton G. Trends and indicators in the changing health care marketplace, 2004 update. The Henry J. Kaiser Family Foundation. April 2004.

2. Narrow WE, Rae DS, Robins LN, Regier DA. Revised prevalence estimates of mental disorders in the United States: using a clinical significance criterion to reconcile two surveys' estimates. Arch Gen Psychiatry. 2002;59(2):115-23.

3. Kessler RC, Barber C, Birnbaum HG, et al. Depression in the workplace: effects on short-term disability. Health Aff (Millwood). 1999;18(5):163-71.

4. Martin JK, Blum TC, Beach SRH et al. Subclinical depression and performance at work. Soc Psychiatry Psychiatr Epidemiol. 1996;31:3-9.

5. Burton WN, Conti DJ. The real measure of productivity. Bus Health. 1999; 17-34-36.

6. Burton WN, Conti DJ, Chen C, et al. The role of health risk factors and disease on worker productivity. J Occup Environ Med. 1999;41:863-77.

7. Stewart WF, Ricci JA, Chee E, et al. Cost of lost productivity work time among US workers with depression. JAMA. 2003;289:3135-44.
8. Greenberg PE, Kessler RC, Birnbaum HG, et al. The economic burden of depression in the United States: how did it change between 1990 and 2000? J Clin Psychiatry. 2003;64(12):1465-75.

9. Kisely S, Linden M, Bellantuono C, Simon G, Jones J. Why are patients prescribed psychotropic drugs by general practitioners? Results of an international study. Psychol Med. 2000;30(5):1217-25.

10. Olfson M, Marcus SC, Druss B, Elinson L, Tanielian T, Pincus HA. National trends in the outpatient treatment of depression. JAMA. 2002;287(2):203-09.

11. Frank RG, Huskamp HA, McGuire TG, Newhouse JP. Some economics of mental health "carve-outs." Arch Gen Psychiatry. 1996;53:933-37.

12. Sturm R. Tracking changes in behavioral health services: how have carveouts changed care? J Behav Health Serv Res. 1999;26:360-71.

13. New federal guidelines seek to help primary care providers recognize and treat depression. Agency for Health Care Policy and Research (AHCPR) of the Department of Human Services. Hosp Community Psychiatry. 1993;44(6):598.

14. Young AS, Klap R, Sherbourne CD, Wells KB. The quality of care for depressive and anxiety disorders in the United States. Arch Gen Psychiatry. 2001;58:55-61. 